\title{
SYSTEMIC LUPUS ERYTHEMATOSUS
}

\author{
By T. F. MCCaRThY, M.D., B.Sc., M.R.C.P.E., and D.- P. MisRa, M.B., B.S. \\ from the Stockport Clinical Area
}

Systemic lupus erythematosus is the result of a disease process involving the collagen connective tissues of the body, which causes a type of degeneration resembling a fibrinoid change. This change in connective tissue is seen in varying degrees in a wide variety of conditions collectively described as collagen diseases. Since the discovery of the lupus erythematosus cell by Hargraves more experience in its demonstration has facilitated the diagnosis in cases which did not originally fit into the usual disease pattern and has revealed that the disease is more common than was suspected. It is proposed to discuss the clinical manifestations and clinical pathological changes of five cases of systemic lupus erythematosus seen in the last two years.

\section{Case Histories}

\section{CASE I}

A woman, aged 38 years, was well until March of 1956, when she developed a febrile illness with right-sided pain on movement, but not on coughing, and not associated with sputum or breathlessness. She was told that she had pneumonia and was treated with penicillin for a week with improvement, but she remained in bed for six weeks. During convalescence there was morning stiffness in the fingers and more severe pain and some swelling in the knees. These subsided spontaneously, however, and after the illness had lasted three to four months she returned to her work as a shop assistant, but had to cease work again after a month as swelling recurred in her knees. In August 1956 she attended hospital as an outpatient with marked acrocyanosis, active arthritis in the knees and painless swelling of the finger joints. Following a period of rest there was a dramatic improvement both in respect of her joints and her general health and three months later the only abnormal findings in the locomotor system were small effusions in the knees. The blood sedimentation rate was still raised to $70 \mathrm{~mm}$. (Westergren one-hour reading).

One week later she again became febrile and ill, pneumonia was again diagnosed and treated with penicillin and six weeks' bed rest. At the end of this period she was referred to the chest clinic, $\stackrel{\vec{\circ}}{-}$ where an elevated right diaphragm was discovered $\vec{\omega}$ and a bronchogram was carried out. This showed no collapse and the condition was thought to be a을 resolving pneumonia. The joint symptoms, how -3 . ever, recurred following this illness and fine crepi- $\omega$ tations appeared in both lower zones of the chest. She was admitted to hospital for further assess- - v ment. The only other feature in the history is that for three years she has been subject to Raynaud's ${ }_{0}^{N}$ attacks in the fingers.

On examination her general condition was fair, $\vec{Z}$ there was a mild generalized lymphadenopathy ando the skin of the feet and nose showed a slight scaling $\Phi$ and was mottled and mauve. The heart appeared normal, the blood pressure was $105 / 55 \mathrm{~mm}$. and examination of the chest revealed crepitations $\frac{9}{6} \vec{\omega}$ the right base. The liver was palpable, but 100 other abnormality was revealed in the abdomen. The nervous system appeared normal. The meta-O carpo-phalangeal joints and the inter-phalangeal joints were swollen, but had a full range of move-ō ment and numerous small nodules were palpable $\frac{0}{\mathbb{Q}}$ on the long flexor tendons. The wrists were swollen with a full range of movement which was, $\overrightarrow{0}$ however, painful. The left tarsal joints were 3 swollen; the remaining limb joints and spine? appeared normal.

\section{Investigations}

Blood count 15/7/57: Hb 80 per cent., W.B.C.s 5,600 , polymorphonuclears 64 per cent., lymphocytes 27.5 per cent., large mononuclears 7 per cent.,응 eosinophils I.5 per cent. Platelets abundant M.C. H.C. 33 per cent. Serum albumin 2.5 per cent., serum globulin 4.9 per cent. Serum bilirubin $>$ $0.2 \mathrm{mg} . / 100 \mathrm{ml}$. Thymol turbidity 17 units. Alkaline phosphatase 9.5 units/100 ml. Electro- No phoresis showed a general increase in the globulin most marked in the gamma globulin. Blood urea $34 \mathrm{mg}$./ $100 \mathrm{ml}$. Urea clearance 87 per cent. of $\omega$ average normal. Urine sterile, test for protein negative, an occasional epithelial cell seen in theo centrifuged deposit. Blood sedimentation rate on $\Phi$ successive occasions $90 / 200 \mathrm{~mm} ., 97 / 200 \mathrm{~mm} .,+$ $86 / 200 \mathrm{~mm}$. (Westergren). Wassermann and Kahn ${ }_{0}^{\circ}$ 
reactions were negative. A test for L.E. cells was positive. Chest $\mathrm{X}$-rays showed a raised right dome of the diaphragm, with fine mottling throughout both lower zones.

It was concluded that the patient was suffering from acute systemic lupus erythematosus and steroid therapy was commenced (prednisolone I 5 mg. daily). The dosage was reduced and she was discharged to continue treatment as an out-patient. To date she remains well, the chest $\mathrm{X}$-ray remaining unchanged.

\section{Comments}

Pulmonary manifestations in systemic lupus erythematosus tend to be variable and may be complicated by secondary pyogenic infections, especially in the terminal stages. Pleuritic pain is common and may be an early symptom. The pleurisy may be dry or associated with a pleural effusion usually small. L.E. cells have been found in both pleural and pericardial effusions. X-ray sometimes shows basal shadows suggesting plate atelectasis, and there is impaired diaphragmatic movement, resulting eventually in elevation and fixation of the diaphragm.

Pleural involvement occurred in all of our cases, but case I presented with a febrile illness with right-sided chest pain, diagnosed as pneumonia and treated with penicillin. In spite of initial improvement, the chest symptoms persisted for some weeks after the antibiotic treatment was stopped. A further chest episode occurred about eight months later, for which she was treated in the same way and which ran a similar course. An $\mathrm{X}$-ray six weeks later demonstrated a raised right dome of the diaphragm and screening showed restricted movement. Bronchography showed distortion of the bronchi, but no evidence of collapse. At a follow-up review six weeks later she was found to have coarse crepitations at both bases and an $\mathrm{X}$-ray showed the right dome of the diaphragm to be still raised and basal mottling to be present. These radiographic appearances have persisted to date:

The pulmonary manifestations of this case thus closely resemble those of the two cases described by P. Ellman and L. Cudkowicz, where febrile pulmonary episodes occurred early in the course of the disease, and where migrating pulmonary shadows and impaired diaphragmatic movements gave a resemblance to pulmonary infarction. However, in these cases the pulmonary changes subsided, but in this case the signs still persist.

The other manifestations noted in this case were arthritis, peripheral vascular phenomena with acrocyanosis and an enlarged liver.

\section{CASE 2}

A housewife, aged 28 years, was first seen in the out-patient department on $31 / 3 / 55$. Intermittent chest pain and dyspnoea on exertion had been present for a year and for four months she had had a poor appetite and had lost $I \frac{1}{2}$ stones in weight. On examination muscular weakness of both arms, more marked on the right side, with wasting of the intrinsic muscles of the hands, was noticed, and also wasting of the right side of the tongue. No sensory disturbance could be detected, all tendon reflexes were brisk and equal on both sides, the plantar responses were indefinite. The patient was admitted a few days later for investigation. No abnormality was detected in any other system and a chest X-ray showed a slight left-sided pleural reaction, and the blood count showed a $\mathrm{Hb}$. of 64 per cent. with R.B.C.s three million and W.B.C.s 5,000. Examination of the C.S.F., X-ray of the skull and the W.R. were carried out on account of the neurological findings, but revealed no abnormality. She was discharged on $20 / 4 / 55$ for out-patient supervision, the only treatment being for her anaemia.

In May 1956 she complained of pain in the back and in her fingers, hips and thighs. Mild swelling of the interphalangeal joints was noted, but X-ray of the hands showed no changes suggestive of rheumatoid arthritis. She was readmitted in June 1956 for further review; the clinical findings were as noted before.

Plasma proteins, albumin 4.39 g./ $100 \mathrm{ml}$., globulin $5.6 \mathrm{~g}$. $/ 100 \mathrm{ml}$. Serum sodium and potassium were within the normal range and liver function tests were normal. The blood count showed normal red cells and a leucocytosis of I I ,000 with 80 per cent. polymorphs. Examination of the blood and sternal marrow showed numerous L.E. cells.

The diagnosis of lupus erythematosus having been made, treatment was commenced with 300 mg. of cortisone daily. This was gradually reduced to $75 \mathrm{mg}$. and the patient remains under outpatient supervision on this dosage. She is at present very well, but the neurological features remain unchanged.

\section{Comments}

Neurological changes have previously been reported as occurring in systemic lupus erythematosus. The lesions in the central nervous system have been described by Glaser (1952) as being due to a disseminated endarteritis which involves the small vessels of the arterial tree. Focal and generalized seizures in the absence of uraemia have been described and also transient cranial nerve paralyses, hemiparesis and aphasia.

One of the cases, a boy of 13 years, had a history 
of epilepsy of eight years' duration prior to the onset of a nephrotic syndrome, investigation of which led to the diagnosis of systemic lupus erythematosus.

Case 2, although referred because of chest symptoms, was found on examination to have muscular weakness of both arms, wasting of the intrinsic muscles of the hands and right-sided hemiatrophy of the tongue. There were no sensory disturbances, the deep reflexes were increased and plantar responses indefinite. These findings could occur in progressive muscular atrophy, which the case thus resembles. There was no clinical evidence of involvement of the pyramidal tract and all neurological changes could be explained by affection of the anterior horn cells at various levels, including the 12th cranial nerve nucleus. In this case intermittent chest pain was present for 16 months before the onset of arthritis suggested the diagnosis.

\section{CASE 3}

A mentally retarded boy, aged $\mathrm{I} 3$ years, who had been an inmate of an epileptic colony for two years was admitted to hospital on $5 / 1 / 57$. There was a history of petit mal from the age of four years. During attacks the child was still, did not respond to commands or hear spoken words and his eyelashes fluttered. There was no aura, he did not fall, there was no incontinence and no loss of memory. He had had six major attacks during this period, in which he fell to the ground and had convulsions. He was treated with tridione and was well controlled. On the day before admission a nurse at the colony noticed that he had oedema of the ankles. When seen in hospital he had, in addition, puffiness of the face, vesicles at the angle of the mouth and was pyrexial. Small inguinal and axillary glands were present. He was found to have a blood pressure of $150 / 1$ I 0 and albuminuria.

After observation it was decided to discontinue tridione in view of the albuminuria, oedema, hypertension and remittent pyrexia. The oedema cleared, but the other signs persisted. He developed a systolic murmur, swelling and stiffness of the elbows and interphalangeal joints.

\section{Investigations}

The urine showed albuminuria, red blood cells and numerous hyaline and granular casts. Blood count: red blood cells 4,370,000 per $\mathrm{cm}$., white blood corpuscles 4,200 per cm., haemoglobin 54 per cent., polymorphs 49 per cent., lymphocytes 45 per cent., large mononuclears 6 per cent. Plasma proteins 7 g./100 ml., albumin 1.6 g./100 $\mathrm{ml}$. Alpha I globulin $0.6 \mathrm{~g} . / 100 \mathrm{ml}$, alpha 2 globulin $0.9 \mathrm{~g} . / 100 \mathrm{ml}$., beta globulin $0.8 \mathrm{~g} . / 100 \mathrm{ml}$., gamma globulin 3.1 g./100 ml., total globulin
5.4 g./100 ml. Serum sodium 139 m.eq./L., serum potassium 4.4 m.eq./L., serum chlorides 93 m.eq./L. Chest X-ray showed an effusion at the $\stackrel{D}{\Omega}$ left base. Blood urea $30 \mathrm{mg}$. per cent., standard $\subseteq$ urea clearance 26 per cent. of average normal function. A buffy coat film of the peripheral blood showed numerous L.E. cells.

\section{Treatment}

On admission a course of penicillin was started, followed by erythromycin, but the temperature failed to respond; it did, however, settle during a course of salicylates, but became elevated again when the course was stopped. Prednisolone was started on $9 / 3 / 57$. The patient became apyrexial the next day and his general condition improved rapidly, the systolic murmur disappeared and the pleural effusion absorbed. The course has been maintained to date and the patient's condition remains satisfactory. His blood pressure is now 130/90. The total protein is elevated $(8.8 \mathrm{~g} . / 100$ $\mathrm{ml}$.) and the albumin globulin ratio is unchanged. The peripheral blood still shows numerous L.E cells and the urine contains a trace of albumin, a few red cells and an occasional granular cast.

\section{Comments}

Renal involvement usually takes the form of nephrosis and advancing kidney damage may cause uraemia, one of the two main causes of death if. this condition. L. C. Hill (I957), describing the renal lesions, states that impaired renal function occurred in ro out of $\mathrm{I} 5$ patients tested and that hypertension was rare. Albuminuria was common, but that occurring early and even if accompanied by red blood cells and a few granular and hyaline casts in the urine might be a temporary febrile phenomena. Dubois (1956) suggests that even the more severe nephropathies may occasionally be helped by treatment. Joske (1956) and Muehrcke et al. (1956) have, however, shown that renal lesions can arise and progress during steroid therapy and that they are usually irreversible.

Case 3 presented with signs of renal impairment and although the oedema disappeared, despite steroid therapy, the urine still contains albumin, red blood cells and casts. It thus seems that the improvement brought about by the steroid therapy has been mainly symptomatic.

\section{CASE 4}

A housewife, aged 48 years, was admitted as an emergency in August I955. She had a long history extending over five years of listlessness, weakness and loss of appetite with a gradual loss of weight. Five months previously she developed acute pains in her wrists and fingers, followed by swelling of the wrists and the interphalangeal joints. This was 
shortly followed by pain and swelling in the knee and ankle joints. Two months later she complained of cough and a purulent sputum, which was bloodstained on occasions. Other haemorrhagic manifestations followed: melena, haematuria on four occasions and severe menorrhagia. One week before admission she complained of sore throat and an erythematous rash appeared on the chest, back and with the characteristic butterfly distribution on the face. On examination the patient looked thin and pale and had ulceration of the mouth and pharynx. She was febrile with a temperature ranging from $97^{\circ} \mathrm{F}$. to $102.6^{\circ} \mathrm{F}$. The heart was regular, there were no murmurs and a tachycardia of 120 per minute was present. Crepitations were heard at both lung bases and there was some impairment of percussion note on the left. Other systems showed no abnormality.

\section{Investigations}

$\mathrm{X}$-ray of the chest showed obliteration of the left costophrenic angle, the sputum was negative for tubercle bacilli and the urine showed numerous red blood cells, but no casts. A mild anaemia was present, $\mathrm{Hb} 7 \mathrm{I}$ per cent. and R.B.C.s 3.2 millions. There was a leucopenia, 3,600 cells of which 82 per cent. were polymorphs. The serum albumin was $3.5 \mathrm{~g} / 100 \mathrm{ml}$. and the globulin was also $3.5 \mathrm{~g}$./100 ml. Examination of the peripheral blood showed the L.E. phenomena.

Cortisone was given in large doses, but the patient failed to respond and died soon after admission. Autopsy confirmed the diagnosis of systemic lupus erythematosus.

\section{Comments}

This case was extremely ill when first seen, being, in fact, in the terminal stages of her illness.

Haemorrhages from the mucous surfaces in this disease were noted by William Osler. Beside haemoptysis, this case had haemorrhages from the gastro-intestinal and urino-genital tracts on a number of occasions. In the absence of thrombocytopenia these manifestations are best explained by the injury caused to the vascular endothelium by the disease process.

\section{CAse 5}

A housewife, aged 33 years, was referred to a surgical out-patient session on account of acute abdominal pain. There she was found to have a three weeks' history of left-sided chest pain, sore throat and night sweats. For five years she had been complaining of recurring stiffness and pain in the joints. She was febrile and ill, dullness and diminished breath sounds were present at the, left base, the spleen was enlarged to three fingers' breadth below the costal margin and was tender, palmar erythema was noted and also diffuse swelling of the thyroid gland. Shoulder, metacarpal, metatarsal and the phalangeal joints were swollen and tender. The chest X-ray showed a left-sided pleural reaction and she was admitted to a general medical ward.

There was a family history of two sisters suffering from rheumatoid arthritis.

\section{Investigations}

Blood count (15/10/56): R.B.C.s 4,540,000 per c.mm., Hb. 86 per cent., W.B.C.s 6,400 per c.mm. Serum albumin 2.5 g./ $/ 100 \mathrm{ml}$., serum globulin $6.4 \mathrm{~g} . / 100 \mathrm{ml}$. L.E. cells seen in moderate numbers in the peripheral blood. Blood urea $25 \mathrm{mg}$./100 ml. Fasting blood sugar $72 \mathrm{mg}$. per cent. Urine showed no albumin, a few red blood cells, but no casts. Throat swab: culture showed normal flora.

Treatment was commenced with cortelan, 50 $\mathrm{mg}$. daily and reduced after $\mathrm{I} 8$ days to $37 \frac{1}{2} \mathrm{mg}$. of cortisone daily. She was discharged for outpatient supervision on this dosage in good general condition. Her spleen was still enlarged, but was no longer tender, and the chest X-ray remained unchanged.

An exacerbation of her condition occurred in August 1957, when she was readmitted to the general medical ward with acute upper abdominal pain, right-sided chest pain and progressive dyspnoea. Examination revealed impairment of resonance and diminution of air entry and vocal resonance at the right base. A chest X-ray showed loss of translucency in this area consistent with patchy inflammatory change. The abdomen was soft and the spleen was not felt on this occasion. The dosage of cortisone was increased to $200 \mathrm{mg}$. daily and her condition improved. She was discharged on a daily dosage of $50 \mathrm{mg}$. of cortisone and has since remained well.

\section{Comments}

William Osler as early as 1895 described the visceral manifestations of systemic lupus erythematosus, including the gastro-intestinal crises. Brown et al. (1957) reported gastro-intestinal symptoms in over one-third of a series of cases. The symptoms were mild in the majority of cases, but severe enough to suggest small gut obstruction in five cases. They suggest the symptoms were due to localized ileus of the duodenum and upper jejunum and all cases responded to conservative measures and general treatment.

Case 5 presented with upper abdominal pain of such severity as to suggest a surgical condition and when readmitted was again complaining of severe abdominal pain. The abdominal condition subsided on both occasions with conservative measures and steroid therapy. 


\section{Summary}

All the cases described had features which led to the presumptive diagnosis being made clinically, and in every case L.E. cells were demonstrated in the peripheral blood. In one case the diagnosis was confirmed at autopsy.

High fever, loss of appetite and weight, painful swollen joints and pleural involvement were common to all. Splenic enlargement and ulceration of the mucous membrane of the mouth was noted in one case and peripheral vascular phenomena and hepatic enlargement in another. The characteristic butterfly rash on the face occurred only once. Other interesting features have been discussed in the footnote to each case. Although widespread joint involvement was common, $\mathrm{X}$-ray failed to demonstrate any lesions in the affected joints. Examination of the blood showed mild to moderate hypochromic anaemia and a leucocyte count ranging from 4,000 to 5,000 per c.mm. The B.S.R. was raised in all cases, ranging from 63 to $105 \mathrm{~mm}$. (Westergren one-hour reading). Plasma proteins were raised ( 7 to $10 \mathrm{~g} . / 100 \mathrm{ml}$.), with the rise mainly in the globulin fraction, a finding in keeping with reported series. In those cases in which plasma proteins were repeated they were found to be uninfluenced by steroid therapy.

Since the L.E. cell phenomena was first demonstrated by Hargraves et al. (I948) several new techniques have been introduced. The test is now being widely used and there are a number of conditions other than systemic lupus where it is found to be positive. Positive L.E. cell tests have recently been described in rheumatoid arthritis by Friedman et al. (1957). One of our cases, which is not described here, had painful deformity of the small joints of the hands of six years' duration. She had a mild hypochromic anaemia, but no other visceral manifestations were noted. L.E. cells were found in the peripheral blood. She is still under observation, but is at present considered to be a case of rheumatoid arthritis.

Dubois (1956) states, on the other hand, that, despite recently introduced refinements of tests,
L.E. cells are not found in all patients with the disease. In all the cases L.E. cells were found in the peripheral blood and we felt that the test, taken in conjunction with the clinical findings, is of the greatest value.

Regarding the management of cases, the consensus of opinion at present favours the use of conservative measures in milder cases. In the acute stages bed rest is essential with the necessary symptomatic treatment. The joint manifestations may be helped by suitable splintage and salicylate therapy. Pneumonic episodes should first be treated with appropriate antibiotics. In this series all cases were acutely ill and it was felt that steroid $\overrightarrow{\vec{T}}$ therapy was indicated. Apart from the case which $\stackrel{\omega}{\sigma}$ lived only a short while after admission, all re- $\overline{8}$ sponded to large doses of steroids and were able to 3 . be discharged on a reduced dosage under outpatient supervision. An exacerbation of symptoms occurring in case 5 while on maintenance therapy was controlled by increasing the steroid dosage. in As symptoms abated it was found possible to once $N$ more reduce the dosage.

While steroids have undoubtedly been life- saving in the acute exacerbations, no evidence has $Z$ been found of alteration in the underlying pathological processes.

We wish to thank Drs. R. M. Fulton and J. R. Allan for their kindness in allowing us to see the patients and use the case notes, and we ax $\mathscr{G}$ especially grateful to Dr. Fulton for his advice anc encouragement.

\section{REFERENCES}

BROWN, C. H., SHIRLEY, E. K., and HASERICK, J. B. (1957), Gastroenterology, 31, 649.

DUBOIS, E. L. (1956), Ann. intern. Med., 45, 163.

ELLMAN, P., and CUDKOWICZ, L. (1954), Thorax, 9, 46.

FRIEDMAN, A. I., et al. (1957), Ann intern. Med., 46, I I 13.

GLASER, G. H. (1952), Arch. Neurol. and Psychiat, 67, 745.

HARGRAVES, M. M., RICHMOND, H., and MORTON, R. (1948), Proc. Mayo Clin., 23, 25.

HILL, L. C. (1957), Brit. med. F., $2 ; 726$.

JOSKE, R. A. (1956), Proc. roy. Soc. Med., 49, 329.

MUEHRCKE, et al. (1956), Proc. roy. Soc. Med., 49, 327.

OSLER, W. (1885), Lancet, i, 415, 459, 504.

OSLER, W. (1895), Amer. F. Med. Sci., r10, 629.

Bibliography continued from page 587-David K. Brooks, M.B., B.S.

JOEKES, A. M. (1957), Proc. roy. Soc. Med., 50, 496.

KNOWLES, H. C., and KAPLAN, S. A. (1953), Arch. intern. Med., 92, 189.

KOLFF, W. J., and BERK, H. T. J. (r944), 'Artificial Kidney, Dialyser with Great Area,' Geneesk, Gids., Vol. 21.

KOLFF, W. J. (r947), 'New Ways of Treating Uraemia,' J. and A. Churchill Ltd., London.

LOWE, K. G. (1952), Lancet, i, 1086.

MATHE, G., and HAMBURGER, J., ' Ciba Foundation Symposium on the Kidney.'
McSWINEY, P. R., and PRUNTY, F. T. G. (1957), F. Endocr., Ю I6, 28.

MERONEY, W. H., and HERNDON (1954), F. Amer. med. Ass., I55, 877 .

MERRILL, J. P. (1955), 'The Treatment of Renal Failure,' Grune and Statton, New York.

MILNE, M. D., and YELLOW LEES, H. (1953), Lancet, ii, 791

OLIVER, J. (1953), Amer. F. Med., 15, 535.

SKEGGS, L., and LEONARDS, J. R. (1948), Science, 108, 212.

STOCK, R. J. (1952), Bull. N.Y. Acad. Med., 28, 507.

SWAN, R. C., and MERRILL, J. P. (1953), Medicine, 32, 215. 